\title{
A Quad-Element UWB-MIMO Antenna with Band-Notch and Reduced Mutual Coupling Based on EBG Structures
}

\author{
Wenjing Wu (D), Bo Yuan (D), and Aiting Wu \\ Institute of Antenna and Microwave Technology, Hangzhou Dianzi University, Hangzhou 310018, China \\ Correspondence should be addressed to Bo Yuan; yuanbo@hdu.edu.cn
}

Received 28 June 2017; Revised 19 September 2017; Accepted 9 December 2017; Published 25 February 2018

Academic Editor: Giorgio Montisci

Copyright (C) 2018 Wenjing Wu et al. This is an open access article distributed under the Creative Commons Attribution License, which permits unrestricted use, distribution, and reproduction in any medium, provided the original work is properly cited.

\begin{abstract}
A compact planar quad-element ultrawideband (UWB) antenna with a band-notch and low coupling for multiple-input multipleoutput (MIMO) system is proposed in this paper. The antenna consists of four circular monopoles with modified defected ground plane and a periodic electromagnetic band gap (EBG) structures. The proposed EBG structures are modified from the traditional mushroom-like ones, comprised of patterns of grids on the top patch, the metallic ground plane, and several vias that connect the top and bottom plane. It is printed at the center of the dielectric substrate to lower electromagnetic coupling between the parallel elements. Besides, by etching four crescent ring-shaped resonant slots on the radiators, a sharp band-notched characteristic is achieved. From the experimental results, the $-10 \mathrm{~dB}$ bandwidth of the antenna is extended covers from 3.0 to $16.2 \mathrm{GHz}$, with a sharp notched band at $4.6 \mathrm{GHz}$. And the isolation is greater than $17.5 \mathrm{~dB}$ between its elements, with a peak gain of $8.4 \mathrm{~dB}$ and a peak efficiency of $91.2 \%$. Moreover, it has a compact size of $0.6 \lambda \times 0.6 \lambda \times 0.016 \lambda$ at $3 \mathrm{GHz}$ and could be a good candidate for portable devices.
\end{abstract}

\section{Introduction}

Since Federal Communications Commission (FCC) released the spectrum from 3.1 to $10.6 \mathrm{GHz}$ for commercial applications [1], ultrawideband (UWB) technology has drawn considerable attention due to its merits of low complexity, low-power consumptions, capability of high data rate, low interference, good time-domain resolution, and reduction of severe multipath effect [2]. Although UWB communication system makes use of huge frequency bands, the permitted power spectral density of the UWB signal is rather limited to avoid interference with other systems, such as the frequency band from 4400 to $4990 \mathrm{MHz}$, which is adopted in large capacity microwave relay trunk network. Multipleinput-multiple-output (MIMO) technology enables the transmission of data over multiple channels and increases the channel capacity without additional power requirements; thus, it has been widely used in modern wireless communication system [3]. Furthermore, compact and planar antenna designs are of great demand since they are easier to integrate with wireless devices [4].

As a key technology for next-generation communication systems, MIMO technique can increase the capability and reliability without additional power or spectrum [5]. To achieve good performance and compact structure, good isolation between closely-spaced antennas is required for MIMO communication systems [6]. In [4], a compact quadelement wideband antenna with slotted ground plane is presented. By etching a modified slotted ground plane, the bandwidth is extended covers from 2 to $6 \mathrm{GHz}$ with a compact size of $0.33 \lambda \times 0.33 \lambda \times 0.01 \lambda$ at $2 \mathrm{GHz}$, but the isolation is only $14 \mathrm{~dB}$ between its elements. In [7], a wideband MIMO antenna with common elements suitable for WiFi and LTE wireless access point application is proposed. It consists of four microstrip feedline-printed monopole antennas with common radiating element and a ring-shaped ground plane; the impedance bandwidth is enhanced from 1.8 to $2.9 \mathrm{GHz}$ by common element particular design. However, it only 


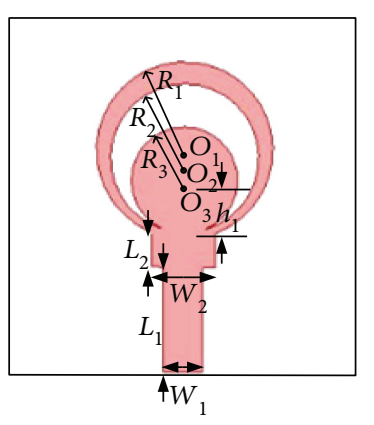

(a) (b)

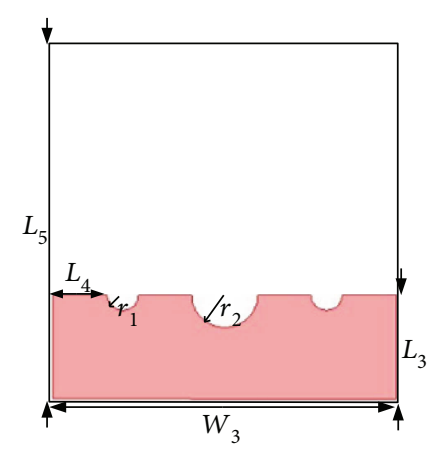

Figure 1: Geometry and parameters of a single element. (a) Front view. (b) Back view. Dimensions (unit: $\mathrm{mm}$ ): $W_{1}=3.0, L_{1}=8.0$, $W_{2}=4.9, L_{2}=2.7, h_{1}=4.0, R_{1}=6.8, R_{2}=5.7, R_{3}=4.1, W_{3}=28.5$, $L_{3}=8.8, L_{4}=4.5, L_{5}=28.5, r_{1}=1.3$, and $r_{2}=2.75$. Note. $O_{1}, O_{2}$, and $\mathrm{O}_{3}$ are the center of the circle with radius $R_{1}, R_{2}$, and $R_{3}$, respectively. The following are the distances: $d_{1}=\left|O_{1}-O_{2}\right|=0.6$ and $d_{2}=\left|O_{2}-O_{3}\right|=0.7$.

results in isolation of $15 \mathrm{~dB}$ in the operating frequency band. In [8], a four-element MIMO patch antenna is designed for $2.45 \mathrm{GHz}$ band operation. For the purpose of antenna miniaturization, it adopts complementary split-ring resonator (CSRR) loading on its ground plane, which reduces the single-element antenna size by $76 \%$. But, the isolation of the antenna only achieves $-10 \mathrm{~dB}$. In [9], a dual element stacked patch antenna is designed for MIMO technology, it achieves a high isolation, and the minimum isolation reaches $31 \mathrm{~dB}$ mainly due to the orthogonal polarization modes of the two excited ports. Nevertheless, the relative operating frequency bandwidth is only $4.3 \%$ from 3.65 to $3.81 \mathrm{GHz}$ and the overall dimension is $0.99 \lambda \times 1.05 \lambda \times 0.03 \lambda$ at $3.65 \mathrm{GHz}$ which is obviously large in miniaturization portable devices.

In this paper, a compact UWB-MIMO antenna with a band-notch and reduced mutual coupling is presented and fabricated. The initial design of a single element includes a circular monopole at the top layer of the dielectric substrate and a modified defected ground structure at the bottom layer to obtain an ultrawideband. Besides, a crescent ring-shaped resonant slot is etched on the surface of the circular monopole to achieve a band-reject to inhibit the interference of large capacity microwave relay trunk network. The orthogonal placement of the elements can ensure the low coupling between the orthogonal element (e.g., 1-2 and 1-4) and a $3 \times 3$ array electromagnetic band gap (EBG) structure can ensure high isolation between the parallel elements (e.g., 13 and 2-4). From the experimental results, the proposed antenna has ultrawideband covers from 3.0 to $16.2 \mathrm{GHz}$, the band-notch centered at $4.6 \mathrm{GHz}$ covers from 4.0 to $5.2 \mathrm{GHz}$, and good isolation of $17.5 \mathrm{~dB}$ between every two elements is achieved. Besides, radiation pattern, gain, efficiency, envelope correlation coefficient (ECC), total active reflection coefficient (TARC), mean effective gain (MEG), diversity gain (DG), and channel capacity loss (CCL) are measured and calculated.

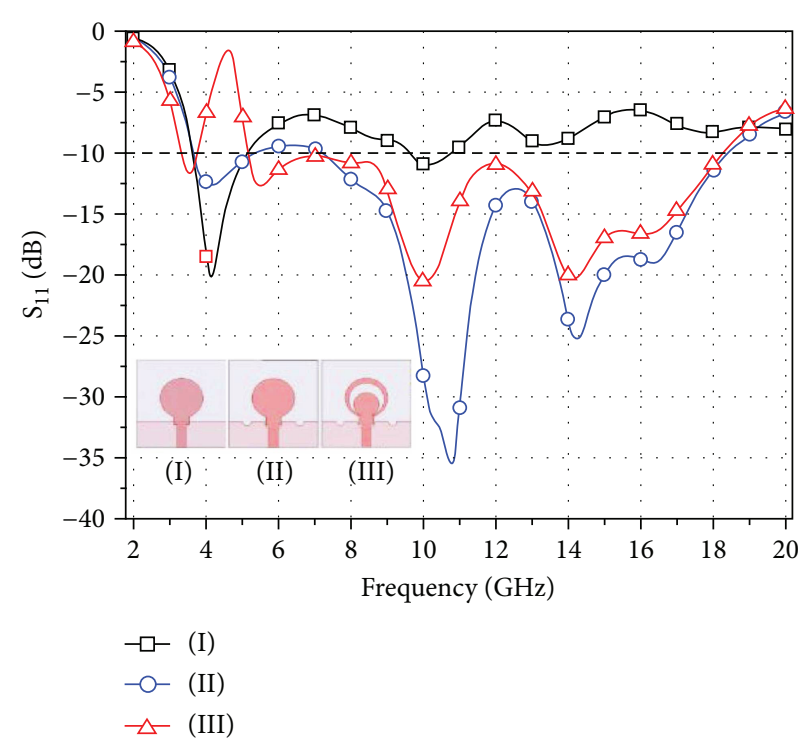

FIgURE 2: Evolution of single element of UWB-MIMO antenna and its $S_{11}$ characteristics.

\section{Proposed Antenna Configuration}

The proposed antenna is fabricated on the low-cost FR4 substrate with a relative permittivity of 4.4 , thickness of $1.6 \mathrm{~mm}$, and loss tangent of 0.02 . Electromagnetic simulator HFSS is used for calculating S-parameters, gain, efficiency, radiation pattern, ECC, TARC, MEG, DG, and CCL, while the dispersion characterization of surface waves propagating on the EBG structures is investigated by CST MWS.

2.1. Single-Element Antenna. The geometry of a single element of the four port antenna is shown in Figure 1. The evolution of the element to obtain an ultrawideband and a band-notched at $4.6 \mathrm{GHz}$ is shown in Figure 2. A printed circular monopole is adopted as the basic element for the antenna; from Figure 2, one can conclude that it radiates at 4.0 GHz and with a bandwidth of $1.46 \mathrm{GHz}$. The shape of the ground plane of the circular monopole radiator is a rectangle with dimensions of $W_{3} \times L_{3}$, as shown in Figure 2 (case I). To achieve an ultrawideband resonance, a big semicircle with radius of $r_{2}$ and two small semicircles with radius of $r_{1}$ are etched on the rectangle ground. The circular monopole radiator benefits from this defected ground structure which has an effect on impedance matching; thus, its simulated bandwidth is expanded covers from 3.3 to $18.0 \mathrm{GHz}$ below $-10 \mathrm{~dB}$ impedance bandwidth level, which is shown as case II in Figure 2. In order to inhibit the interference of large capacity microwave relay trunk network, a crescent ringshaped resonant structure is etched on the surface of the circular monopole antenna as shown in case III in Figure 2. The slot acts as a quarter (guided) wavelength parallel opencircuit transmission line that shorts the antenna at the frequency band from 4.0 to $5.2 \mathrm{GHz}$. The band-notch characteristics at the frequency band are obtained by etching a crescent ring-shaped resonant slot from the circular monopole of the antenna. The length of the slot is about $\lambda / 2$ at the center 


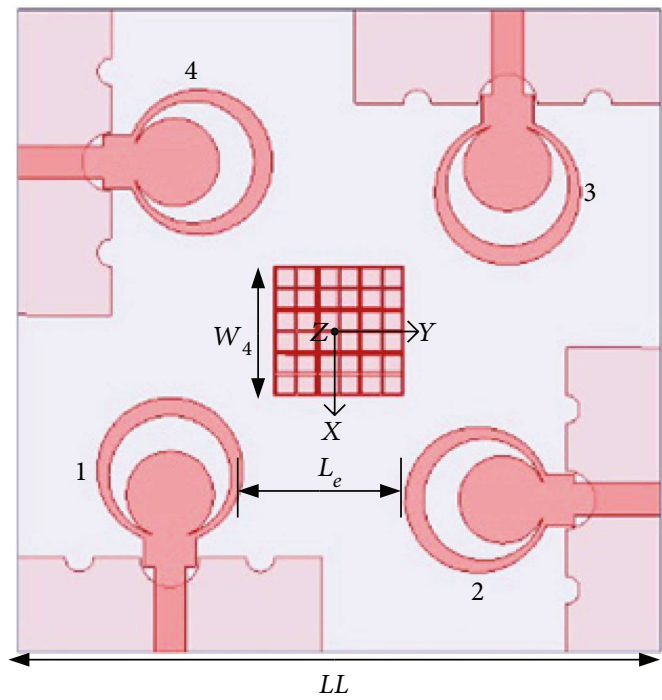

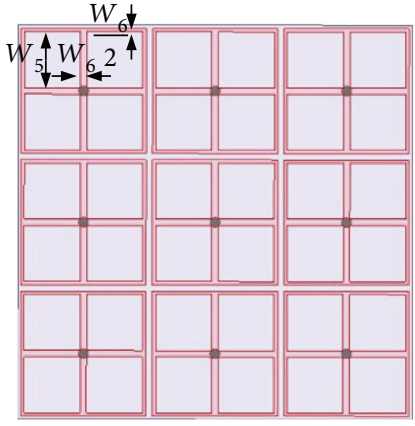

(b)

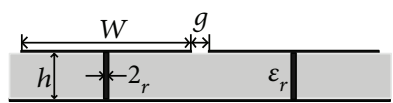

(d)

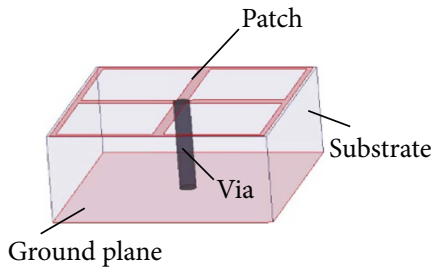

(c)

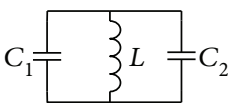

(e)

(a)

Figure 3: (a) Geometry and parameters of a four-port UWB-MIMO antenna. (b) A $3 \times 3$ EBG array structure. (c) Geometry of a unit cell. (d) Parameters of a unit cell. (e) The equivalent parallel LC resonant circuit. Dimensions (unit: $\mathrm{mm}$ ): $W_{4}=12.1, L L=60, L_{e}=15.3$, $W_{5}=1.75, W_{6}=0.2, W=3.9, g=0.1, h=1.6$, and $r=0.15$.

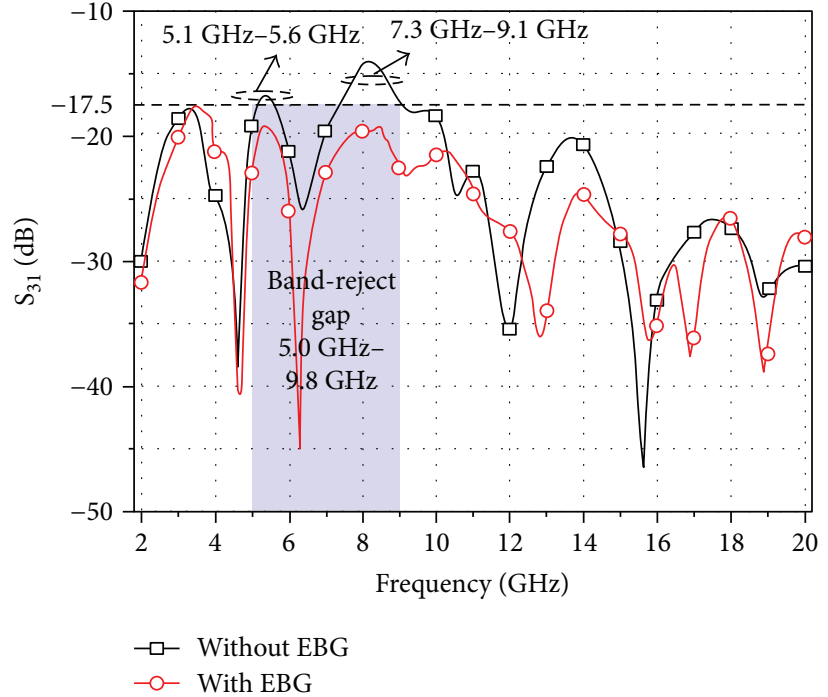

(a)

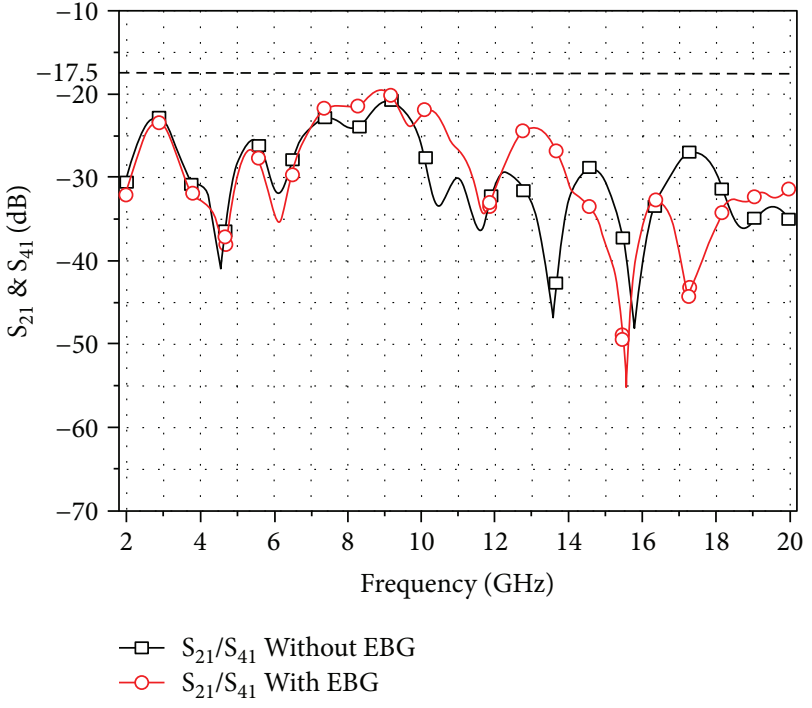

(b)

FIGURE 4: The comparison of the simulated isolations with and without EBG structures. (a) Isolation of the parallel-element: $S_{31}$. (b) Isolation of the orthogonal-element: $S_{21} / S_{41}$.

frequency of the notched band and can be calculated by the following formulas:

$$
\begin{aligned}
\frac{\mathrm{LL}_{2}+\mathrm{LL}_{3}}{2} & =\frac{c}{2 f_{\text {center }} \sqrt{\varepsilon_{\text {eff }}}}, \\
\varepsilon_{\text {eff }} & =\frac{\varepsilon_{r}+1}{2},
\end{aligned}
$$

where $\mathrm{LL}_{2}$ is the outer arc length of the etched slot that can be derived by trigonometric function of other geometric parameters as follows: $\mathrm{LL}_{2}=2\left(\pi-\arccos \left(\left(h_{1}+d_{2}\right) / R_{2}\right)\right) R_{2}$, the geometric meanings of parameters $h_{1}, d_{2}$, and $R_{2}$ are illustrated in Figure 1(a), and $\pi$ and $\arccos \left(\left(h_{1}+d_{2}\right) / R_{2}\right)$ are in radian measurement; $L L_{3}$ represents the inner arc length of the etched slot, its mathematical formula as follows: $\mathrm{LL}_{3}=2\left(\pi-\arccos h_{1} / R_{3}\right) R_{3}, h_{1}$, and $R_{3}$ are also illustrated in Figure 1(a), and $\arccos \left(h_{1} / R_{3}\right)$ is in radian measurement too; $c$ is the speed of the light; $f_{\text {center }}$ is the center frequency of the notched band; the value of relative permittivity $\varepsilon_{r}$ is $4.4 ; \varepsilon_{\text {eff }}$ is effective dielectric constant of the microstrip, and it is simplified from a formula for dielectric constant of the uniform medium. According to 


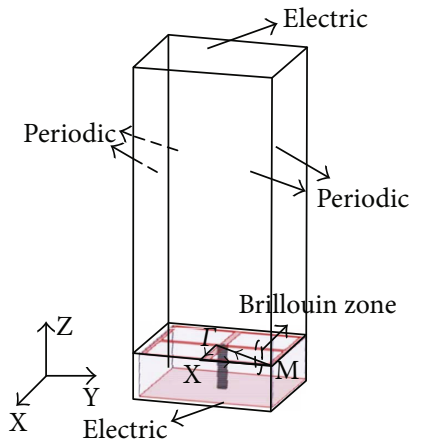

(a)

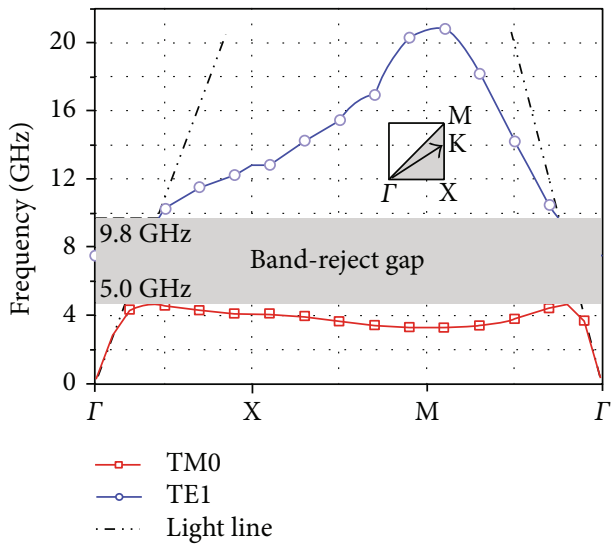

(b)

FIGURE 5: The band-reject gap property of the mushroom-like EBG structure. (a) The settings of a unit cell in CST MWS. (b) Simulated surface wave band structure for a unit cell.

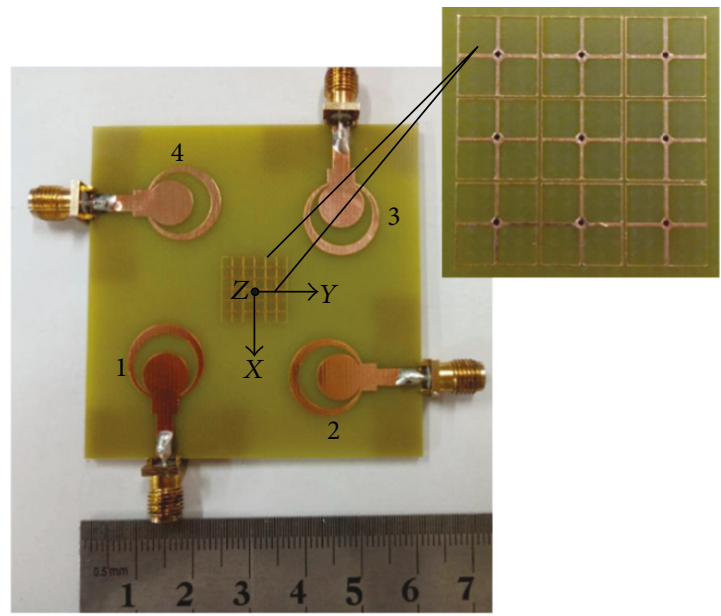

(a)

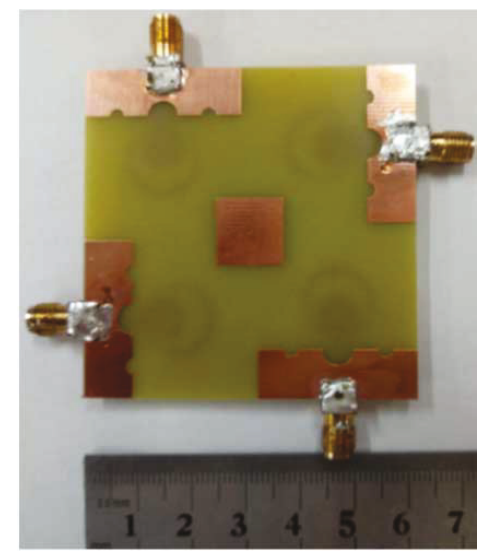

(b)

FIGURE 6: Photographs of fabricated proposed antenna. (a) Front view. (b) Back view.

the center frequency of $4.6 \mathrm{GHz}$, the parameters of $R_{2}, R_{3}$, $d_{2}$, and $h_{1}$ are calculated initially. Then, the parameters are optimized as $R_{2}=5.7 \mathrm{~mm}, R_{3}=4.1 \mathrm{~mm}, d_{2}=0.7 \mathrm{~mm}$, and $h_{1}=4.0 \mathrm{~mm}$ by HFSS.

2.2. Integration of a Four-Element Antenna. By using the element proposed in the previous section, a simulated model of a quad-element UWB-MIMO antenna is built as shown in Figure 3(a). Individual elements, occupying an area of $0.08 \lambda^{2}$, are placed rotationally and symmetrically in a square substrate with an interval of $90^{\circ}$. As illustrated in Figure 4, the S-parameters between parallel element (i.e., 1-3 and 2-4) exhibit a suppressed isolation, overwhelmingly lower than $17.5 \mathrm{~dB}$ in the frequency band of $5.1 \mathrm{GHz}-$ $5.6 \mathrm{GHz}$ and $7.3 \mathrm{GHz}-9.1 \mathrm{GHz}$. However, the orthogonal arrangement of elements (i.e., 1-2 and 1-4) exhibits good isolation, which is mainly greater than $20 \mathrm{~dB}$ in the whole band. The orthogonal arrangement of elements in the antenna can ensure a good isolation between adjacent elements, which is due to the orthogonal polarization field produced in the elements and the mutual coupling is reduced. However, the parallel elements can produce the symmetrical electromagnetic field and the similar polarization; thus, the power will flow from antenna 1 to antenna 3 (antenna 2 to antenna 4) when they are excited, which leads to the high coupling between parallel elements. In Section 3, the EBG structures are proposed to inhibit the mutual coupling between the parallel elements.

2.3. Investigation of Band-Reject Gap Properties. As it is well known, EBG structures can suppress wave propagation in the space between the elements and produce a band-reject gap. Therefore, a periodic EBG structure is implemented to inhibit the mutual coupling between the parallel elements with the target frequency band of $5.1-5.6 \mathrm{GHz}$ and 7.3-9.1 GHz. The $3 \times 3$ EBG array structures, unit cell structure, geometrical parameters of the unit cell, and the parallel $L C$ equivalent resonant circuit are shown in Figures 3(b)-3(e), respectively. The operation mechanism of this EBG structure can be explained by an equivalent LC 


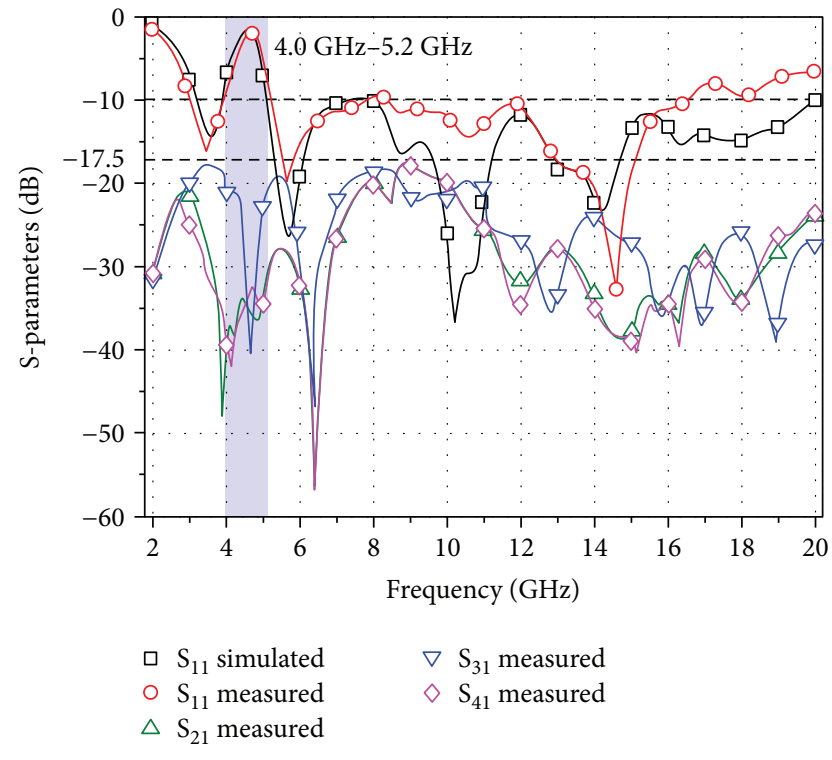

Figure 7: The measured and simulated S-parameters of the fabricated four port MIMO antenna.

resonant circuit: $C_{1}$ is the capacitance of air gap between adjacent EBG unit cells, $C_{2}$ is the capacitance of dielectric gap between top metallic patch and ground plane, and $L$ represents the inductance of metallic vias. For an EBG structure with patch width $W$, gap width $g$, substrate thickness $h$, and dielectric constant $\varepsilon_{r}$, the values of the inductor $L$ and the capacitors (i.e., $C_{1}$ and $C_{2}$ ) are determined by the following formulas [10]:

$$
\begin{aligned}
C_{1} & =\frac{\varepsilon_{0} W}{\pi} \operatorname{arch}\left(\frac{W+g}{g}\right), \\
C_{2} & =\frac{\varepsilon_{0} \varepsilon_{r} W^{\prime}}{\pi} \operatorname{arch}\left(\frac{\sinh \left(\pi\left(W^{\prime}+g\right) / 4 h\right)}{\sinh (\pi g / 4 h)}\right), \\
L & =\mu_{0} h\left\{\frac{1}{\pi}\left[\ln \left(\frac{a+\sqrt{a^{2}-(2 r)^{2}}}{2 r}\right)+\ln 2^{1 / 2}\right]\right\}, \\
f_{0} & =\frac{1}{2 \pi \sqrt{\mathrm{LC}}},
\end{aligned}
$$

where $W^{\prime} \approx\left(1-2 \mathrm{~S} / W^{2}\right) W, \mathrm{~S}=\pi \mathrm{r}^{2}, \mathrm{a}=\mathrm{W}+\mathrm{g}, \mathrm{C}=\mathrm{C}_{1}+\mathrm{C}_{2}$ and $S$ represents the cross-sectional area of via hole, $\mu_{0}$ is the permeability of free space, and $\varepsilon_{0}$ is the permittivity of free space. The initial parameters of the unit cell are calculated by (2), according to the frequency band of $5.1-5.6 \mathrm{GHz}$ and 7.3-9.1 GHz. Then, dispersion diagram is drawn to further study the high-impedance surface of the EBG structures.

According to the initial parameters of the unit cell, dispersion characterization of surface waves propagating on the unit cell of EBG structures is investigated using finite integration technique (FIT) by CST MWS. The boundary conditions of side walls of the unit have to be considered
TABle 1: Comparison with other MIMO antennas.

\begin{tabular}{lcccc}
\hline Ref. & $\begin{array}{c}\text { Element } \\
\text { number }\end{array}$ & $\begin{array}{c}-10 \mathrm{~dB} \\
\text { bandwidth } \\
(\%)\end{array}$ & $\begin{array}{c}\text { Minimum } \\
\text { isolation }(\mathrm{dB})\end{array}$ & $\begin{array}{c}\text { Total } \\
\text { area }\left(\lambda_{0}^{2}\right)\end{array}$ \\
\hline$[4]$ & 4 & 96.2 & 14 & 0.11 \\
{$[7]$} & 4 & 46.8 & 15 & 0.60 \\
{$[8]$} & 2 & 131.0 & 15 & 0.34 \\
{$[9]$} & 2 & 4.3 & 31 & 1.03 \\
{$[10]$} & 4 & 23.9 & 14 & 0.43 \\
This work & 4 & 137.5 & 17.5 & 0.36 \\
\hline
\end{tabular}

periodic, and the boundaries at the top and the bottom of the model are defined as electric conductor, as illustrated in Figure 5(a). In order to cover the frequency band of $5.1-5.6 \mathrm{GHz}$ and $7.3-9.1 \mathrm{GHz}$, the parameters of the unit cell are optimized as follows: $W_{5}=1.75 \mathrm{~mm}, W_{6}=0.2 \mathrm{~mm}$, $W=3.9 \mathrm{~mm}$, and $g=0.1 \mathrm{~mm}$. The numerically simulated $k-\beta$ dispersion diagram of the surface modes propagating in the EBG structure is conducted using CST eigenmode solver, as shown in Figure 5(b). A complete band-reject between the first mode (TM0 mode) and the second mode (TE1 mode) in the frequency band of $5.0-9.8 \mathrm{GHz}$ can be observed. $\Gamma, X$, and $M$ stand for symmetric points in the irreducible Brillouin zone. The $\Gamma-X$ branch represents $\beta_{x} a / \pi$ with $\beta_{y}=0$, the $X-M$ branch represents $\beta_{y} a / \pi$ with $\beta_{x}=\pi / a$, and the $M-\Gamma$ branch represents $\beta_{x} a / \pi$ with $\beta_{x}=\beta_{y}[10-14]$. Because of slow-wave behavior of surface waves, dispersion curves are calculated only in the region under the light line, and the simulated frequency bandreject gap is from 5.0 to $9.8 \mathrm{GHz}$, as shown in Figure 5(b). Therefore, the isolation between the parallel elements has been enhanced from $17 \mathrm{~dB}$ to $20 \mathrm{~dB}$ within the band-reject gap of $5.1-5.6 \mathrm{GHz}$ and $7.3-9.17 \mathrm{GHz}$ when the $3 \times 3 \mathrm{EBG}$ array structures placed at the center of the dielectric substrate, which could be observed in Figure 4(a).

\section{Measurement and Results}

The proposed antenna is fabricated, as shown in Figure 6. Simulated and measured results of the quad-element UWBMIMO antenna system are discussed in this section. The measurements of the proposed antenna are implemented by using Rohde and Schwarz ZVM vector network analyzer.

The simulated and measured S-parameters of the UWBMIMO antenna are shown in Figure 7. The measured Sparameter under $-10 \mathrm{~dB}$ level is from 3.0 to $16.2 \mathrm{GHz}$ with a bandwidth of $137.5 \%$, which is less than the simulated one from 3.0 to $20.0 \mathrm{GHz}$. Deviation of $S_{11}$ curve occurs at high-frequency band between the measured result, and the simulated one is mainly due to the error of fabricating, welding, and testing. And reflection coefficient of the bandnotched antenna at $4.6 \mathrm{GHz}$ is about $-2.4 \mathrm{~dB}$, which can inhibit the interference of large capacity microwave relay trunk network from 4.0 to $5.2 \mathrm{GHz}$. From the curves of Sparameters, it can be observed that the antenna system exhibits a measured minimum isolation of $17.5 \mathrm{~dB}$ between 

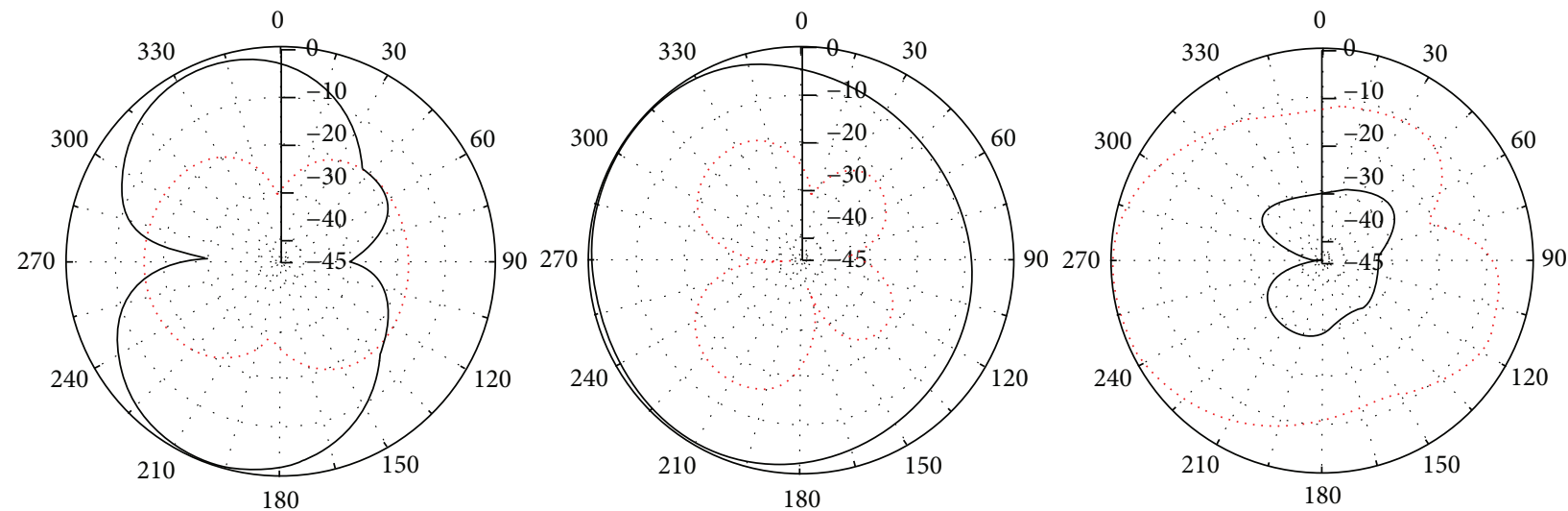

(a)
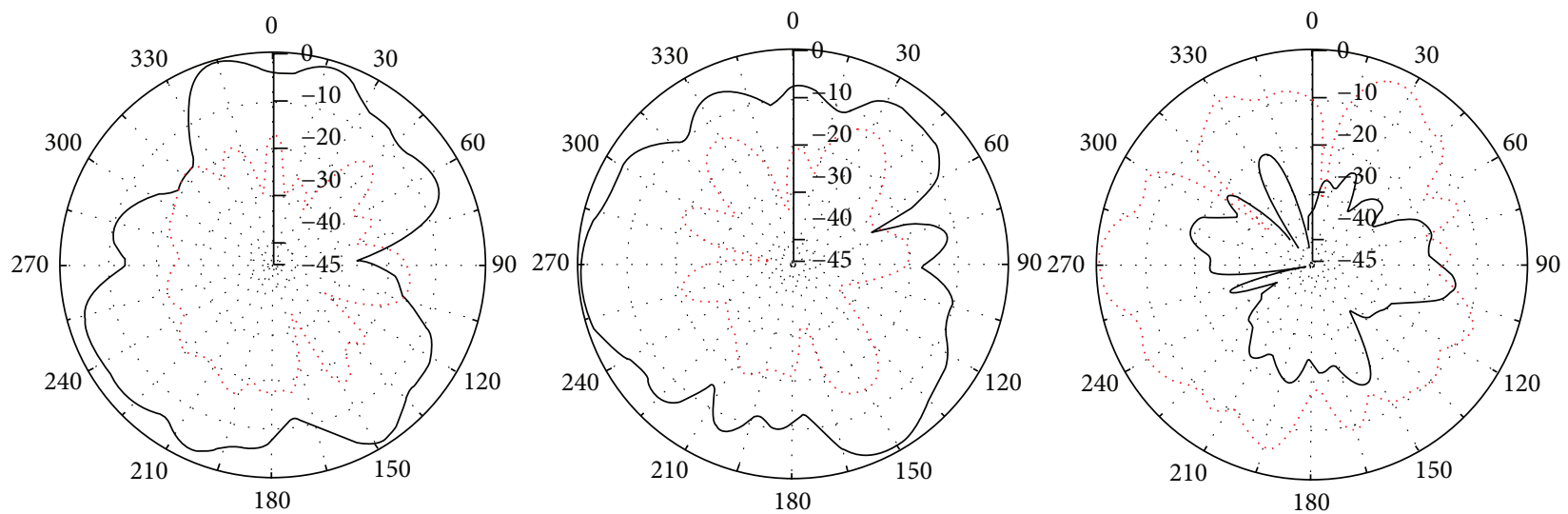

(b)
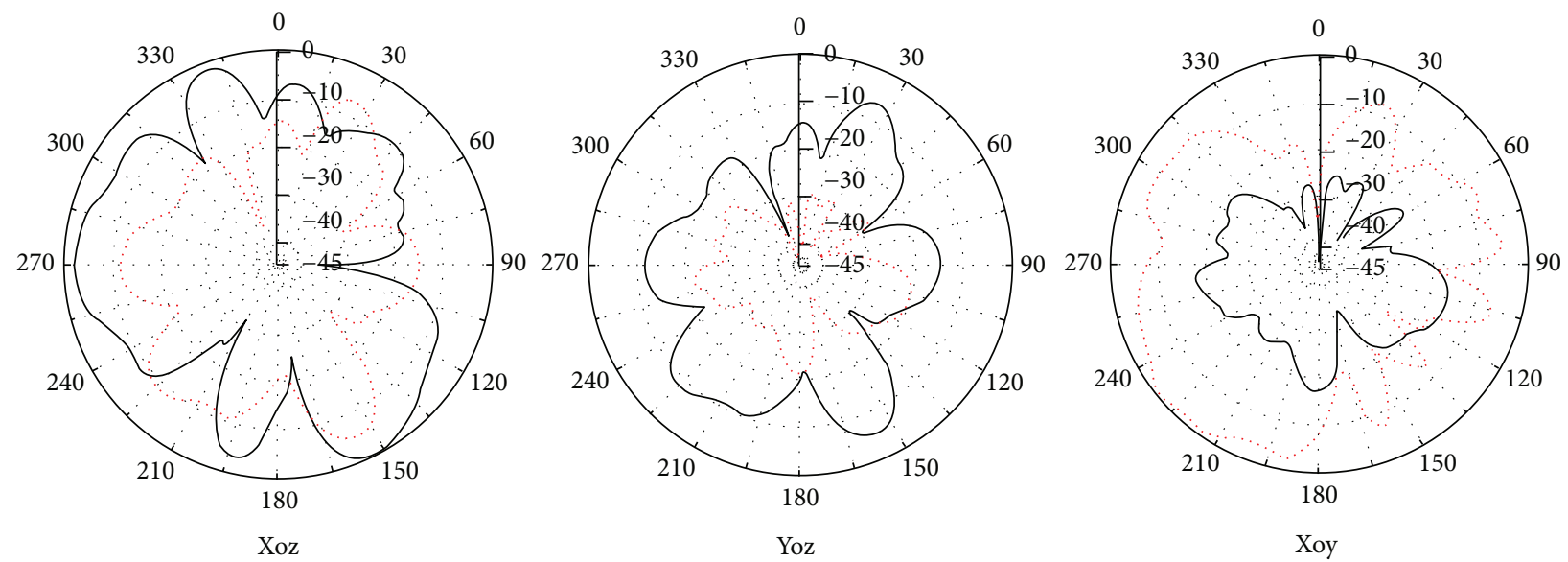

(c)

Phi component

— Theta component

FIGURE 8: Measured radiation pattern of the proposed antenna at (a) 3.5, (b) 10.5, and (c) $16.2 \mathrm{GHz}$ (at two planes of xoz and yoz, where theta component is coplanar radiation pattern; and at xoy plane, where phi component is coplanar radiation pattern).

its elements throughout the operating band. A comparison between the proposed antenna and few other recently reported planar MIMO designs in terms of bandwidth, mutual coupling, and size is shown in Table 1, where $\lambda_{0}$ is the largest free-space wavelength corresponding to the lowest operating frequency of the referenced antennas. It can be observed that the proposed planar MIMO antenna has an excellent bandwidth performance, a good inhibitory ability to rejected frequency band, and has a compact size. 


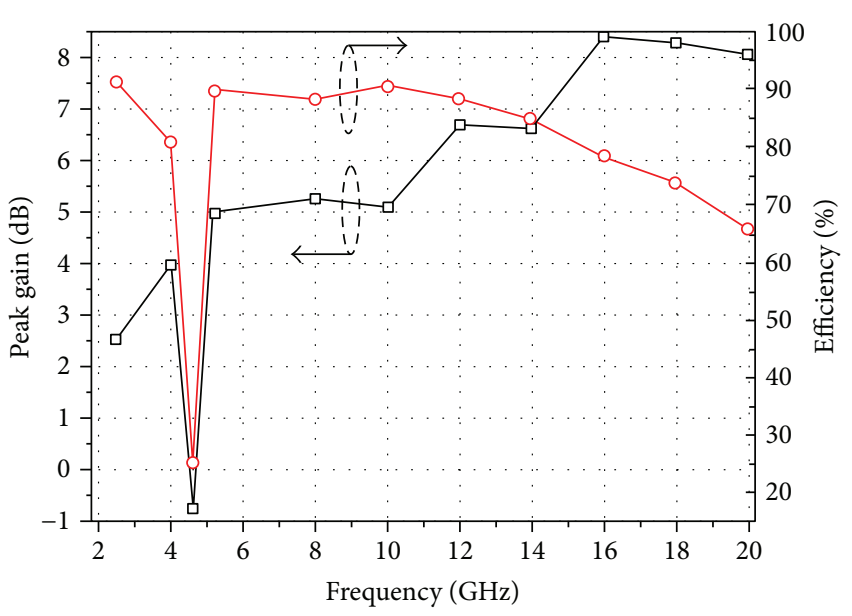

Figure 9: Measured gain and efficiency of the proposed antenna.

Far-field patterns are obtained inside an anechoic chamber for antenna 1 , while the other three elements are terminated with $50 \Omega$ impedances. Port 1 is measured due to the symmetrical of the proposed antenna, which leads to the same patterns when other ports are excited. Measured radiation patterns for xoz-plane, yoz-plane, and xoy-plane at 3.5, 10.5 , and $16.2 \mathrm{GHz}$ are shown in Figure 8. It is observed that cross-polarization at some planes is quite high because of the orthogonal arrangement of the four elements, which leads to the orthogonal of the electrical field. Peak gain and efficiency measurements are also performed and are plotted in Figure 9. Gain measurements show a peak gain of $8.4 \mathrm{~dB}$ at $16 \mathrm{GHz}$, and a peak efficiency of $91.2 \%$ is obtained at $10 \mathrm{GHz}$.

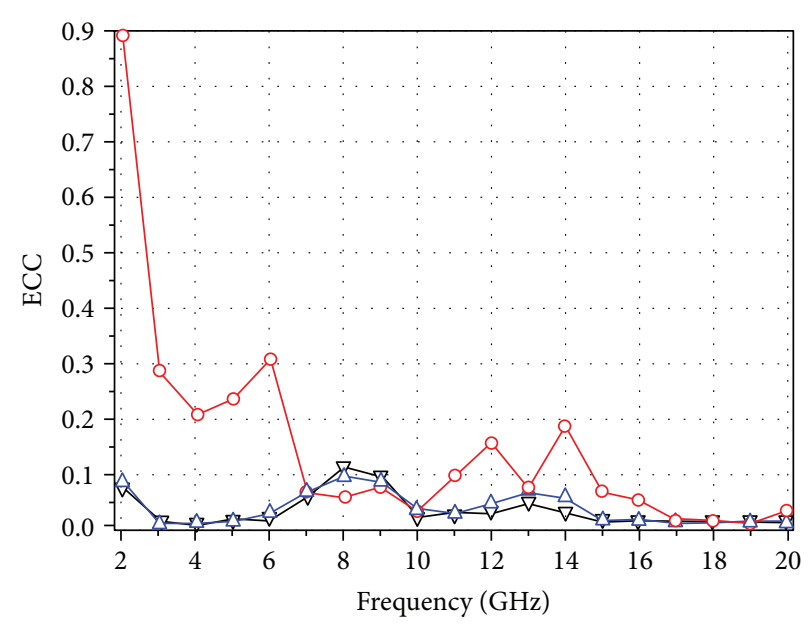

$\rightarrow-\rho_{e 13}$
$\multimap-\rho_{e 12}$
$\triangle \rho_{e 14}$

Figure 10: Simulated ECCs between the elements of the antenna.

The envelope correlation coefficients (ECC), diversity gain (DG), and total active reflection coefficient (TARC) are computed for evaluating the diversity performance of the proposed quad-element MIMO antenna. ECC quantifies the correlation between the branch signals received by different elements, and a lower ECC signifies higher pattern diversity. The envelope correlation coefficient $\rho_{e}$ of the four-antenna system can be given by [15]

$$
\rho_{e}(i, j)=\frac{\left|\int_{\Omega}\left[\mathrm{XPR} \cdot E_{\theta i} E_{\theta j}^{*} P_{\theta}+E_{\Phi i} E_{\Phi j}^{*} P_{\Phi}\right] d \Omega\right|^{2}}{\int_{\Omega}\left\{\mathrm{XPR} \cdot E_{\theta i} E_{\theta i}^{*} P_{\theta}+E_{\Phi i} E_{\Phi i}^{*} P_{\Phi}\right\} d \Omega \times \int_{\Omega}\left\{\mathrm{XPR} \cdot E_{\theta j} E_{\theta j}^{*} P_{\theta}+E_{\Phi j} E_{\Phi j}^{*} P_{\Phi}\right\} d \Omega},
$$

where XPR is the ratio of cross-polarization power, which is defined as $\mathrm{XPR}=P_{\mathrm{V}} / P_{\mathrm{H}} \quad\left(P_{\mathrm{V}}\right.$ and $P_{\mathrm{H}}$ are the vertical component strength of the electric field and the horizontal component strength of the electric field, resp.). $E_{\theta i}$ and $E_{\Phi j}$ are the complex envelops of $\theta$ and $\Phi$ component of farfield radiation patterns, respectively, when the $i$ th port is excited and the other ports are terminated with $50 \Omega$ impedance. $P_{\theta}$ and $P_{\Phi}$ are the probability distributions of the power incident on the antenna in the $\theta$ and $\Phi$ polarizations, respectively. The angle $\Omega$ is defined by $\theta$ in elevation and $\Phi$ in azimuth. ECC is below 0.3 in the working frequency band from 3.0 to $16.5 \mathrm{GHz}$ as shown in Figure 10, and that could ensure the favorable diversity gain (DG) presented in Table 2. TARC is the square root of the sum of all incident powers at the ports minus radiated power and then divided by the sum of all incident powers at the ports of an N-port antenna. TARC can be computed by the following formula, given by [8]

$$
\begin{aligned}
& \Gamma_{a}^{t}=\frac{\sqrt{\sum_{i=1}^{N}\left|b_{i}\right|^{2}}}{\sqrt{\sum_{i=1}^{N}\left|a_{i}\right|^{2}}}, \\
& {[\mathbf{b}]=[\mathbf{S}][\mathbf{a}],}
\end{aligned}
$$

where $a_{i}$ and $b_{i}$ are the incident signals and reflected signals, respectively, $[\mathbf{S}]$ is the antenna's scattering matrix, $[\mathbf{a}]$ is the excitation vector, and $[\mathbf{b}]$ represents the scattered vector. Formula (5) can be written as

$$
\left[\begin{array}{c}
\mathbf{b}_{1} \\
\mathbf{b}_{2} \\
\mathbf{b}_{3} \\
\mathbf{b}_{4}
\end{array}\right]=\left[\begin{array}{llll}
\mathbf{S}_{11} & \mathbf{S}_{12} & \mathbf{S}_{13} & \mathbf{S}_{14} \\
\mathbf{S}_{21} & \mathbf{S}_{22} & \mathbf{S}_{23} & \mathbf{S}_{24} \\
\mathbf{S}_{31} & \mathbf{S}_{32} & \mathbf{S}_{33} & \mathbf{S}_{34} \\
\mathbf{S}_{41} & \mathbf{S}_{42} & \mathbf{S}_{43} & \mathbf{S}_{44}
\end{array}\right]\left[\begin{array}{c}
\mathbf{a}_{1} \\
\mathbf{a}_{2} \\
\mathbf{a}_{3} \\
\mathbf{a}_{4}
\end{array}\right]
$$

According to the four-port MIMO antenna system, TARC is a parameter that refers to the coupling of the 
TABLE 2: Meg and DG of MIMO antenna system.

\begin{tabular}{lccccccccccc}
\hline & \multicolumn{2}{c}{ MEG1 $(\mathrm{dB})$} & \multicolumn{2}{c}{ MEG2 $(\mathrm{dB})$} & \multicolumn{2}{c}{ MEG3 $(\mathrm{dB})$} & \multicolumn{2}{c}{ MEG4 $(\mathrm{dB})$} & \multirow{2}{*}{$\mathrm{DG}\left(\rho_{e 12}\right)$} & \multirow{2}{*}{$\mathrm{DG}\left(\rho_{e 13}\right)$} & $\mathrm{DG}\left(\rho_{e 14}\right)$ \\
$\mathrm{XPD}$ & $0 \mathrm{~dB}$ & $6 \mathrm{~dB}$ & $0 \mathrm{~dB}$ & $6 \mathrm{~dB}$ & $0 \mathrm{~dB}$ & $6 \mathrm{~dB}$ & $0 \mathrm{~dB}$ & $6 \mathrm{~dB}$ & & $6.4 \mathrm{~dB}$ \\
\hline $3 \mathrm{G}$ & -3.6 & -5.7 & -3.5 & -5.6 & -3.7 & -5.8 & -3.6 & -5.6 & $6.0 \mathrm{~dB}$ & $6.2 \mathrm{~dB}$ \\
$9 \mathrm{G}$ & -3.5 & -6.6 & -3.4 & -6.5 & -3.6 & -6.7 & -3.4 & -6.7 & $10.4 \mathrm{~dB}$ & $10.3 \mathrm{~dB}$ & $10.2 \mathrm{~dB}$ \\
$15 \mathrm{G}$ & -4.1 & -7.8 & -4.0 & -7.9 & -4.2 & -7.7 & -4.2 & -7.7 & $8.7 \mathrm{~dB}$ & $8.5 \mathrm{~dB}$ & $8.8 \mathrm{~dB}$ \\
\hline
\end{tabular}
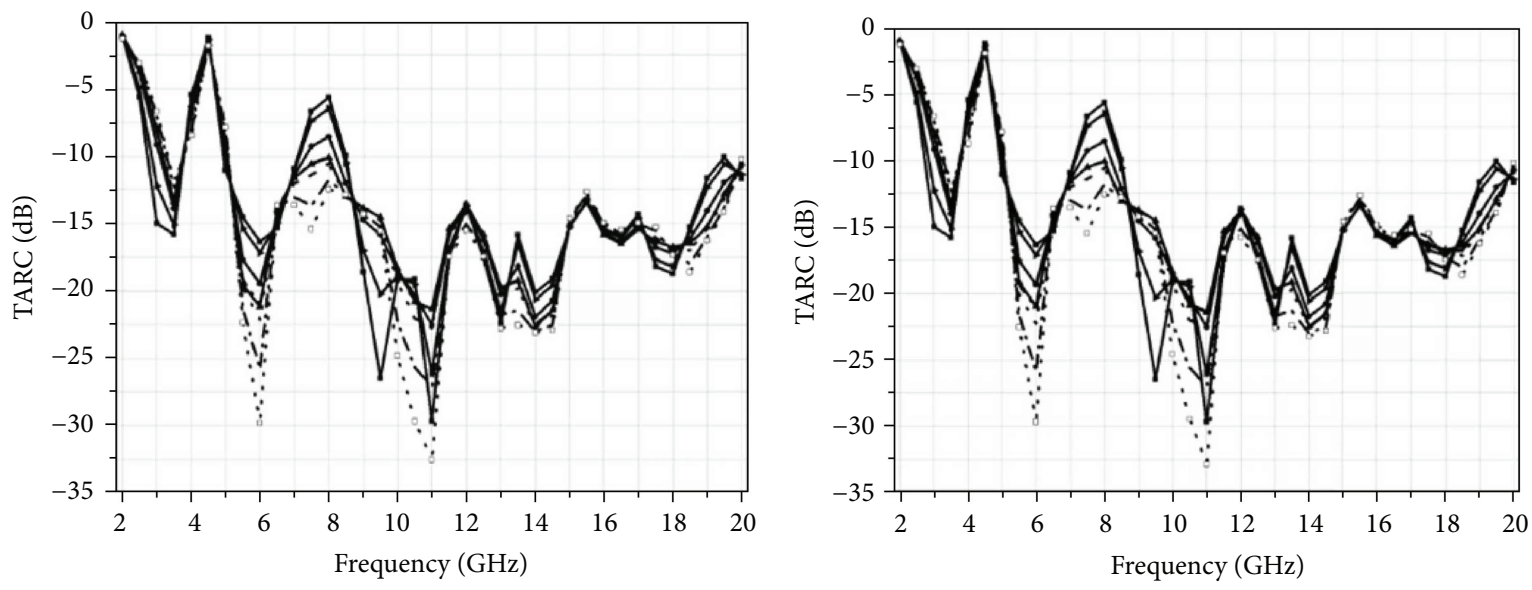

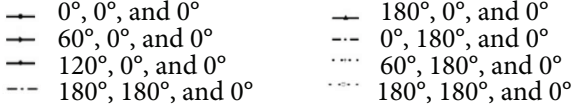

(a)
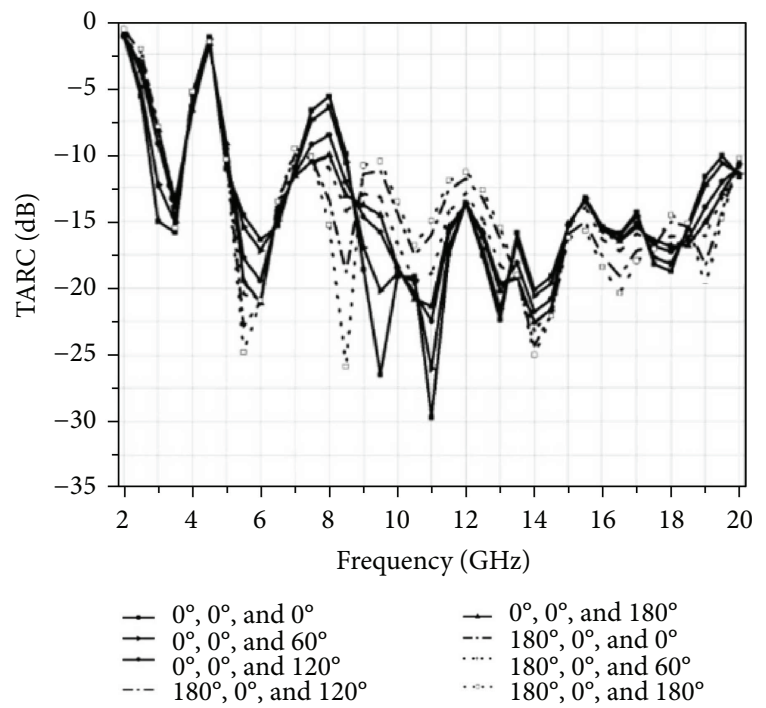

(c)

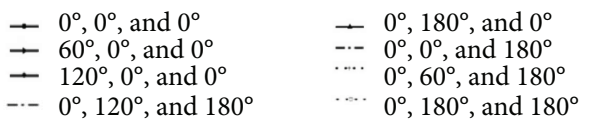

(b)
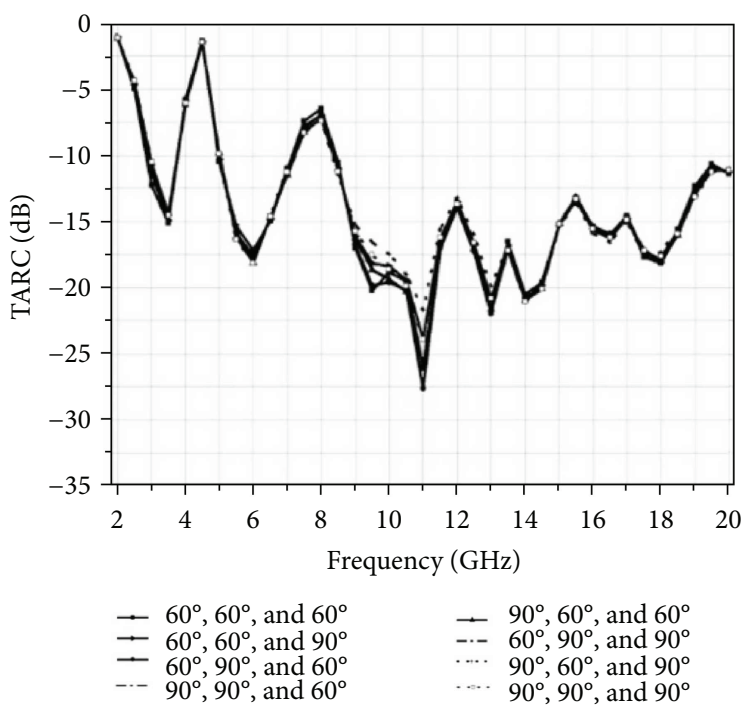

(d)

FIGURE 11: TRAC curves for the proposed MIMO antenna with different phase combinations between the four elements: (a) elements 1 and 4 are in phase; (b) elements 1 and 2 are in phase; (c) elements 1 and 3 are in phase; (4) all elements are out of phase.

ports, and its value is between 0 and 1 , where 0 means all incident power is radiated, but 1 means all incident power is reflected. TARC curves for the proposed MIMO antenna with different phase combinations between the four elements are described in decibels in Figure 11. The excited port 1 is kept at $1 e^{j 0}$, while the other ports (i.e., ports 2, 3, and 4) are excited with different phases. For example, if the legend reads $\left(120^{\circ}, 180^{\circ}\right.$, and $\left.0^{\circ}\right)$, it means that the excited phase of antenna 2 is at $120^{\circ}$ shift with antenna 1 , antenna 3 is at $180^{\circ}$ shift, and antenna 4 is consistent with antenna 1 . As evident from the figures, the simulated TARC curves have an agreement with the $S_{11}$ curve at 
some phases shift (e.g., $180^{\circ}, 0^{\circ}$, and $0^{\circ}, 0^{\circ}, 180^{\circ}$, and $0^{\circ}$, and $0^{\circ}, 0^{\circ}$, and $180^{\circ}$ ) of the excited ports, where more incident power is radiated.

To quantify the average received signal strength for each element, mean effective gains (MEGs) are calculated as the ratio of mean received power to the mean incident power. The MEG of the antenna can be calculated using its twodimensional gain pattern, which is given by [8] as

$$
\mathrm{MEG}=\frac{1}{2 \pi} \int_{0}^{2 \pi}\left[\frac{\Gamma}{1+\Gamma} G_{\theta}\left(\frac{\pi}{2}, \Phi\right)+\frac{1}{1+\Gamma} G_{\Phi}\left(\frac{\pi}{2}, \Phi\right)\right] d \Phi,
$$

where $\Gamma$ is the cross-polarization discrimination (XPD) of the incident field, $G_{\theta}$ and $G_{\Phi}$ are the power gain patterns. The MEG of the proposed antenna is tabulated in Table 2. An XPD of $0 \mathrm{~dB}$ corresponds to outdoor applications and an $\mathrm{XPD}$ of $6 \mathrm{~dB}$ corresponds to indoor applications. As evident from the Table, the antenna has a good MEG performance as deviations between the MEGs of the various elements are both less than $3 \mathrm{~dB}$.

Theoretically, the channel capacity can be improved by increasing the number of antennas of the MIMO system. However, the uncorrelated Rayleigh fading will result in channel capacity loss (CCL) of the MIMO system. The capacity loss $\left(C_{\text {loss }}\right)$ of the four-element MIMO antenna can be evaluated by using the equation as follows $[16,17]$ :

$$
C_{\mathrm{loss}}=-\log 2 \operatorname{det}\left(\psi^{R}\right)
$$

where $\psi^{R}$ is the receiving antenna correlation matrix that is given by

$$
\psi^{R}=\left[\begin{array}{llll}
\rho_{11} & \rho_{12} & \rho_{13} & \rho_{14} \\
\rho_{21} & \rho_{22} & \rho_{23} & \rho_{24} \\
\rho_{31} & \rho_{32} & \rho_{33} & \rho_{34} \\
\rho_{41} & \rho_{42} & \rho_{43} & \rho_{44}
\end{array}\right],
$$

$\rho_{i i}=1-\left|\sum_{n=1}^{4} \mathrm{~S}_{\text {in }}^{*} \mathrm{~S}_{n i}\right|$, and $\rho_{i j}=-\left|\sum_{n=1}^{4} \mathrm{~S}_{i n}^{*} \mathrm{~S}_{n j}\right|$, for $i, j=1,2,3$, or 4 . The simulated and measured capacity losses of the proposed MIMO antenna are shown in Figure 12; it can be seen that the simulated capacity loss is less than $0.4 \mathrm{bits} / \mathrm{s} / \mathrm{Hz}$ in the operating frequency band except for the frequency band of $3.0 \mathrm{GHz}-5.7 \mathrm{GHz}$ and $7.0 \mathrm{GHz}-8.3 \mathrm{GHz}$. Observed from Figure 4 and Figure 9, the isolation of parallel element is 2 to $4.5 \mathrm{~dB}$ lower in the band of $3.0 \mathrm{GHz}-3.8 \mathrm{GHz}$ and 1 to $3 \mathrm{~dB}$ lower in the band of $5.1 \mathrm{GHz}-5.7 \mathrm{GHz}$ than the standard isolation of $22 \mathrm{~dB}$, the radiation efficiency in the band of $3.8 \mathrm{GHz}-5.1 \mathrm{GHz}$ is probably $1 \%$ to $52.8 \%$ lower than lowest $78.2 \%$ efficiency in other operating frequency band, and the isolations of orthogonal element and parallel element in $7.0 \mathrm{GHz}-8.3 \mathrm{GHz}$ are about $0.2 \mathrm{~dB}$ to $2 \mathrm{~dB}$ and $0.1 \mathrm{~dB}$ to $3 \mathrm{~dB}$ lower than the standard isolation of $22 \mathrm{~dB}$, respectively. In addition, the measured one can also be analyzed in the same way. Therefore, the higher isolation and radiation efficiency will induce lower channel capacity loss.

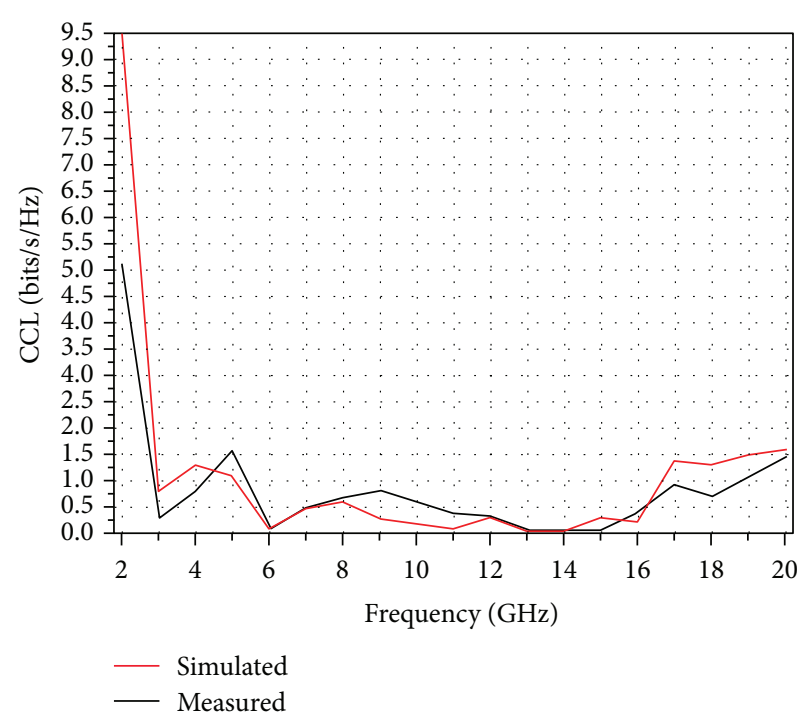

Figure 12: Channel capacity loss for the MIMO antenna.

\section{Conclusion}

In this paper, a compact planar quad-element UWBMIMO antenna with band-notch and reduced mutual coupling based on EBG structures is presented. The antenna is fabricated on a FR4 substrate and occupies a total size of $60 \times 60 \times 1.6 \mathrm{~mm}^{3}$. The antenna system exhibits good impedance matching across the $-10 \mathrm{~dB}$ operating bandwidth. By etching four crescent ring-shaped resonant slots on the radiators, a sharp band-notched characteristic is achieved at $4.6 \mathrm{GHz}$. Low mutual coupling is achieved by orthogonal placement of the elements and loading EBG structures. The radiation efficiency, ECC, TARC, MEG, DG, and CCL have been calculated to evaluate the diversity performance of the proposed MIMO antenna. In short, the quad-element UWB-MIMO antenna with band rejection and high isolation has an application value in modern wireless communication systems.

\section{Conflicts of Interest}

The authors declare that they have no conflicts of interest.

\section{Acknowledgments}

This work was supported by the NSFC under Contract 61501153.

\section{References}

[1] Federal Communications Commision, Federal Communications Commission Revision of Part 15 of the Commision's Rules Regarding Ultra-Wideband Transmission System from 3.1 to 10.6 GHz, ET-Docket, Washington, DC, USA, 2002.

[2] T. Kaiser, F. Zheng, and E. Dimitrov, "An overview of ultrawide-band systems with MIMO," Proceedings of the IEEE, vol. 97, no. 2, pp. 285-312, 2009.

[3] J. Wallace, M. Jensen, A. Swindlehurst, and B. Jeffs, "Experimental characterization of the MIMO wireless channel: data 
acquisition and analysis," IEEE Transactions on Wireless Communications, vol. 2, no. 2, pp. 335-343, 2003.

[4] R. Anitha, P. V. Vinesh, K. C. Prakash, P. Mohanan, and K. Vasudevan, "A compact quad element slotted ground wideband antenna for MIMO applications," IEEE Transactions on Antennas and Propagation, vol. 64, no. 10, pp. 4550-4553, 2016.

[5] R. D. Murch and K. B. Letaief, "Antenna systems for broadband wireless access," IEEE Communications Magazine, vol. 40, no. 4, pp. 76-83, 2002.

[6] S. Zhang, J. Xiong, and S. He, "MIMO antenna system of two closely-positioned PIFAs with high isolation," Electronics Letters, vol. 45, no. 15, pp. 771-773, 2009.

[7] A. MoradiKordalivand, T. A. Rahman, and M. Khalily, "Common elements wideband MIMO antenna system for WiFi/LTE access-point applications," IEEE Antennas and Wireless Propagation Letters, vol. 13, pp. 1601-1604, 2014.

[8] M. S. Sharawi, M. U. Khan, A. B. Numan, and D. N. Aloi, “A CSRR loaded MIMO antenna system for ISM band operation," IEEE Transactions on Antennas and Propagation, vol. 61, no. 8, pp. 4265-4274, 2013.

[9] Y. Gao, R. Ma, Y. Wang, Q. Zhang, and C. Parini, "Stacked patch antenna with dual-polarization and low mutual coupling for massive MIMO," IEEE Transactions on Antennas and Propagation, vol. 64, no. 10, pp. 4544-4549, 2016.

[10] K. Ding, G. Cheng, Q. Dexin, and Q. Yin, "Compact broadband MIMO antenna with parasitic strip," IEEE Antennas and Wireless Propagation Letters, vol. 16, pp. 2349-2353, 2017.

[11] F. Yang and Y. Rahmat-Samii, "Microstrip antennas integrated with electromagnetic band-gap (EBG) structures: a low mutual coupling design for array applications," IEEE Transactions on Antennas and Propagation, vol. 51, no. 10, pp. 2936-2946, 2003.

[12] L. Markley and G. V. Eleftheriades, "A negative-refractiveindex metamaterial for incident plane waves of arbitrary polarization," IEEE Antennas and Wireless Propagation Letters, vol. 6, pp. 28-32, 2007.

[13] S. D. Assimonis, T. V. Yioultsis, and C. S. Antonopoulos, "Computational investigation and design of planar EBG structures for coupling reduction in antenna applications," IEEE Transactions on Magnetics, vol. 48, no. 2, pp. 771-774, 2012.

[14] L. Li, B. Li, H. Liu, and C. Liang, "Locally resonant cavity cell model for electromagnetic band gap structures," IEEE Transactions on Antennas and Propagation, vol. 54, no. 1, pp. 90-100, 2006.

[15] A. Ramachandran, S. Mathew, V. P. Viswanathan, M. Pezholil, and V. Kesavath, "Diversity-based four-port multiple input multiple output antenna loaded with interdigital structure for high isolation," IET Microwaves, Antennas \& Propagation, vol. 10, no. 15, pp. 1633-1642, 2016.

[16] C. H. See, R. A. Abd-Alhameed, Z. Z. Abidin, N. J. McEwan, and P. S. Excell, "Wideband printed MIMO/diversity monopole antenna for WiFi/WiMAX applications," IEEE Transactions on Antennas and Propagation, vol. 60, no. 4, pp. 2028-2035, 2012.

[17] G. Das, A. Sharma, and R. K. Gangwar, "Dual port aperture coupled MIMO cylindrical dielectric resonator antenna with high isolation for WiMAX application," International Journal of RF and Microwave Computer-Aided Engineering, vol. 27, no. 7, article e21107, 2017. 


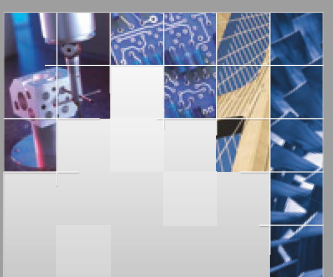

\section{Enfincering}
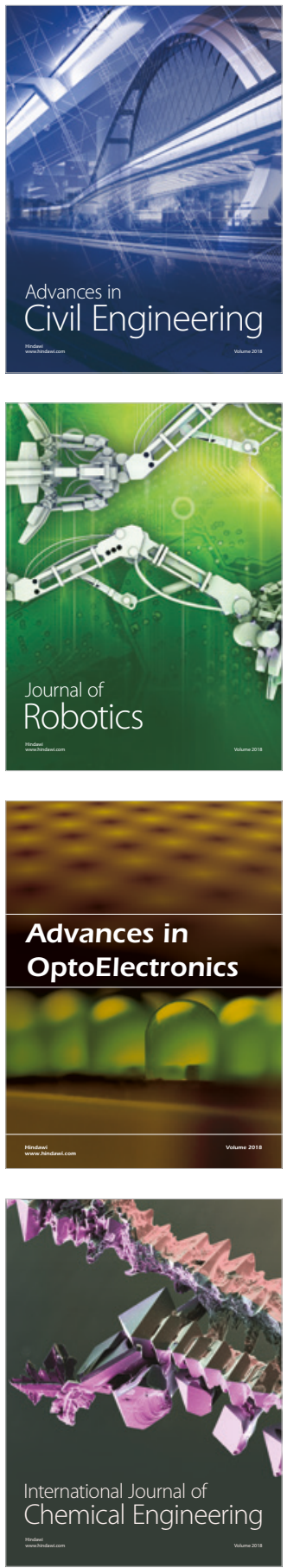

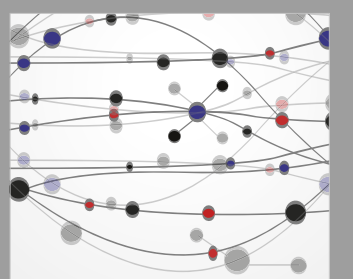

\section{Rotating \\ Machinery}

The Scientific World Journal

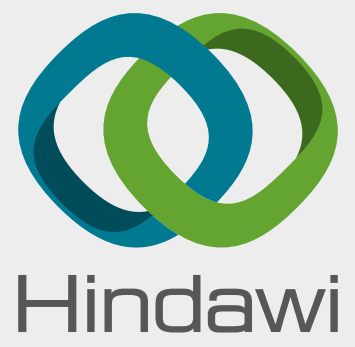

Submit your manuscripts at

www.hindawi.com
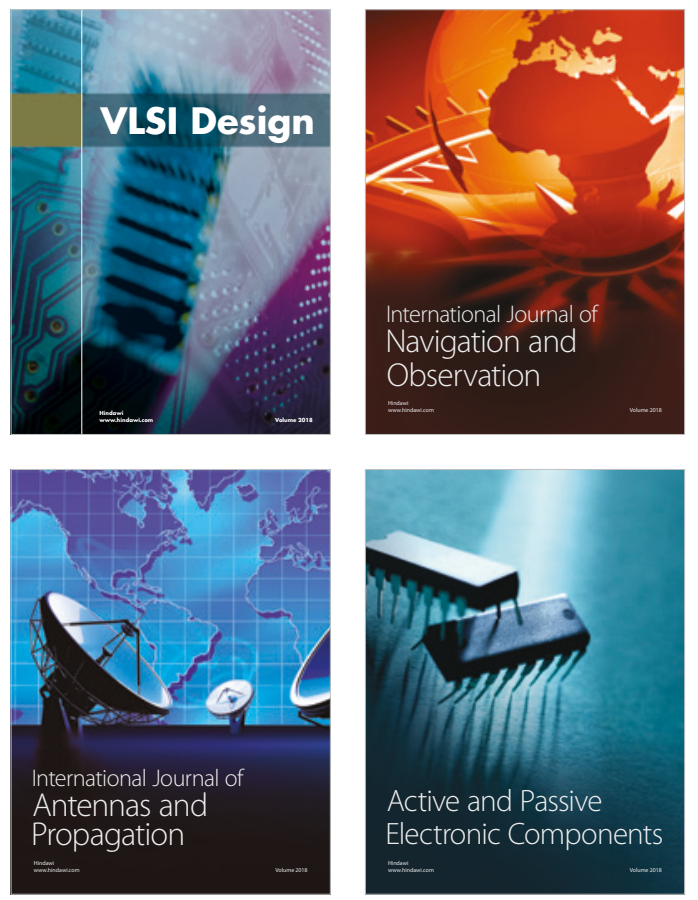
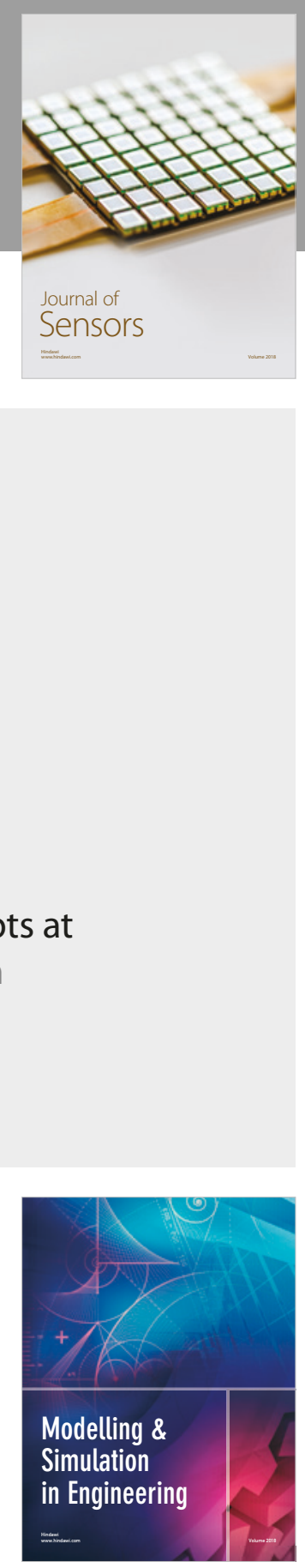

\section{Advances \\ Multimedia}
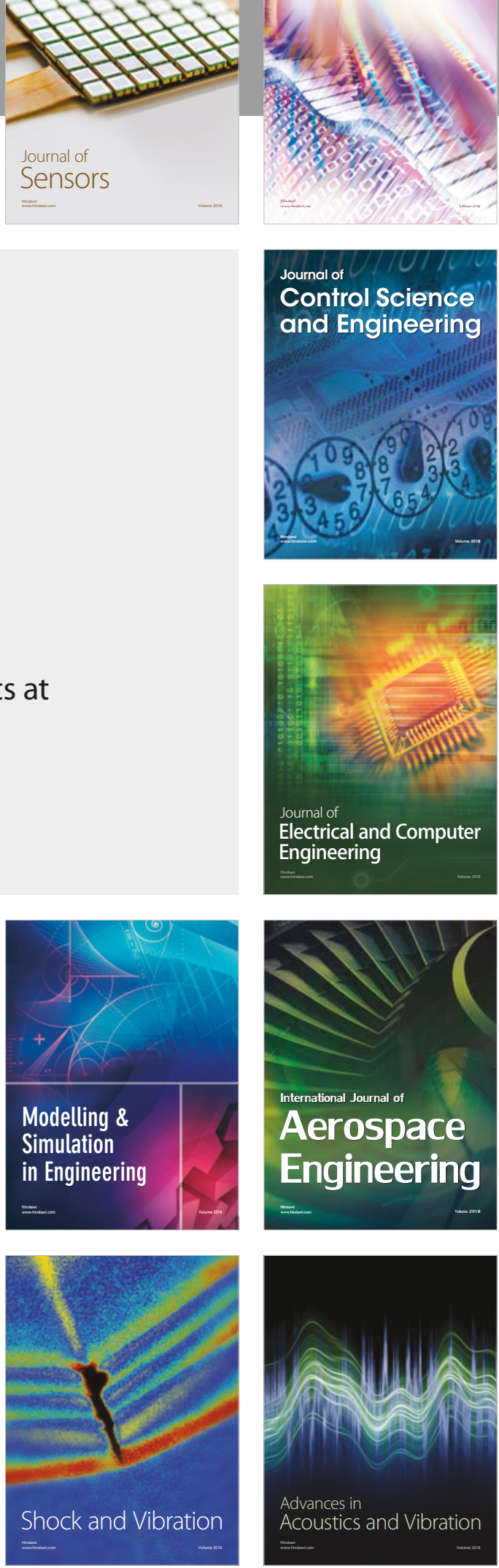